\title{
A Comunicação na Articulação Agroindustrial entre Uma Cooperativa Central, suas Cooperativas Singulares e Cooperados
}

\author{
Diego Neves de Sousa1', Nora Beatriz Presno Amodeo², \\ Alex dos Santos Macedo ${ }^{3}$ e Cleiton Silva Ferreira Milagres ${ }^{4}$
}

Resumo: A comunicação cumpre um papel essencial na articulação dos diferentes níveis da organização para que coordene de forma eficiente a cadeia produtiva sem concorrer por recursos, tirando a potencialidade competitiva da integração vertical cooperativa (Modelo Central - Singulares). Neste estudo, se objetivou analisar a comunicação organizacional na articulação agroindustrial entre uma cooperativa central, suas cooperativas singulares e cooperados. A pesquisa é exploratória-descritiva, utilizando um estudo de caso, com o apoio da técnica de entrevista semiestruturada. Constatou-se que a sobrevivência deste modelo dependerá de como se faz a articulação dos diferentes níveis de organização cooperativa da produção.

Palavras-chaves: comunicação, cooperativas, sistema agroindustrial.

Abstract: Communication plays an essential role in the articulation of different levels of the organization to efficiently coordinate the production chain without competing for resources, taking the competitive potential of the cooperative vertical integration (Central - Singles). This study aimed to analyze organizational communication in agribusiness relation among a Central Cooperative, their Single Cooperatives and members. The research is exploratory-descriptive using a case study, supported by the semi-structured interview technique. It was concluded that the survival of this model (Central - Singles) depends on the linkage between different levels of the cooperative's production organization.

Key-words: communication, cooperatives, agribusiness system.

Classificação JEL: Q13.

1. Analista da Embrapa Pesca e Aquicultura (TO). E-mail: diegocoop@hotmail.com

2. Professora do Departamento de Economia Rural da Universidade Federal de Viçosa (UFV). E-mail: npresno@ufv.br

3. Mestrando do Programa de Pós-Graduação em Administração da Universidade Federal de Lavras (UFLA). E-mail: alexmacedo.ufv@gmail.com

4. Professor da Universidade Federal do Tocantins (UFT). E-mail: cleiton.milagres@hotmail.com 


\section{Introdução}

As cooperativas são formas organizacionais específicas que combinam objetivos empresariais e sociais articulados conjuntamente (VALADARES, 2003; AMODEO, 2006; SOUSA et al., 2014). A gestão cooperativa deve, então, contemplar igualmente esses dois aspectos, atendendo à gestão social e empresarial destas organizações. No entanto, o enfoque empresarial é geralmente priorizado em detrimento do social, chegando este último, às vezes, a ficar num plano secundário. Obviamente, é importante a realização da gestão focada no empresarial, fundamental para atingir os objetivos econômicos da cooperativa e dos seus sócios. Entretanto, é necessária sua complementaridade com a gestão social, a fim de promover ações em que a decisão a ser tomada contemple a realidade, a opinião e os objetivos individuais daqueles que compõem o seu quadro social, não somente de sua diretoria, permitindo ajustar os sistemas de produção individuais às oportunidades de negócio das cooperativas.

Com o apoio de uma eficaz comunicação cooperativa-cooperado, se permite articular adequadamente a cadeia de valor promovendo melhores resultados econômicos. Neste prisma, gestão social e gestão empresarial seriam duas faces da mesma moeda, ou seja, são complementares e imprescindíveis para uma gestão coopera- tiva de êxito, como assevera Amodeo (2006). Para que isso se concretize, a cooperativa necessita estar bem gerida, de tal modo que os dois tipos de gestão sejam igualmente promovidos e de forma complementária, para cumprir com os objetivos das organizações cooperativas.

Com base nos estudos sobre o papel da comunicação na articulação dos diferentes níveis de organização no modelo central-singular de cooperativas apontados por Macedo et al. (2013) e Sousa et al. (2014), pressupõe-se que na estrutura cooperativista exista uma comunicação de relações simétricas e que proporcione melhor e maior contato e intercâmbio entre os integrantes da cooperativa, viabilizando, por meio da própria estrutura, um funcionamento mais participativo e de relações dialógicas. Assim, dentre os modelos e perspectivas teóricas da comunicação que serão apresentadas nesse artigo, aquele que mais se adequaria à estrutura específica das cooperativas e que possibilitaria desenvolver relações "cooperado-cooperativa" num formato mais participativo e dialógico, como classifica Byers (1997), é o da "comunicação como interação", que propõe percorrer um caminho circular entre emissor e receptor, os quais podem adaptar ou ajustar suas mensagens (e, consequentemente, suas ações) por meio da retroalimentação de informações. Ou seja, trata-se de um modelo de mão dupla, que promove a transformação per- 
manente do receptor em transmissor e vice-versa, permitindo um reajuste constante da comunicação. Obviamente, neste modelo, o emissor deixa de controlar as mensagens que serão emitidas, exigindo um compromisso maior na disponibilização das informações necessárias por parte de quem as possua.

A comunicação é uma ferramenta estratégica para viabilizar melhorias na gestão cooperativa, o que apresenta desafios específicos quanto às técnicas utilizadas, sobretudo para evitar o surgimento de barreiras que impeçam o desenvolvimento de fluxos de informação entre os públicos envolvidos no empreendimento cooperativo. Assim, por ser considerado um dos maiores problemas encontrados na gestão cooperativa (SCHNEIDER e HENDGES, 2006; VALADARES, 2009), passa a ser - portanto - tarefa da educação cooperativista encontrar instrumentos de comunicação mais eficientes e adequados à realidade do cooperativismo, como forma de promover melhores resultados.

Segundo Frantz (1983), a realização de um trabalho de comunicação atrelado ao de educação cooperativista é um significativo instrumento a serviço das cooperativas para a eliminação de conflitos, na medida em que oferece aos associados mais possibilidades de articular seus interesses. Além disso, a educação cooperativista tem exatamente o papel de atuar simultaneamente na gestão social e empresarial das cooperativas, com o objetivo de promover melhorias tanto no que se refere ao aumento da participação dos cooperados, quanto na profissionalização da gestão, a fim de fortalecer a sua específica estrutura organizacional. Essa característica do processo comunicativo, por meio da educação cooperativista, pode ser utilizada na capacitação dos sócios, promovendo a participação dialógica e educativa e a busca de equilíbrio entre os interesses dos públicos envolvidos.

No caso das cooperativas agrárias, a informação direcionada aos produtores rurais associados tende, muitas vezes, a ser concentrada pelos dirigentes, já que os cooperados não se reconhecem como donos do empreendimento e os dirigen- tes, por serem os representantes legais da organização, têm mais possibilidades de controlar as informações e alinhá-las aos seus próprios interesses (SOUSA et al., 2014). Esta situação aumenta o risco de comportamentos oportunistas, pois os associados, se não tiverem informações da cooperativa, se não a sentem próxima de seus interesses, não reconhecem seu poder de controle e, consequentemente, não se comprometerão com ela. A fidelização, portanto, depende em parte de como se mantém esta relação nos processos de comunicação.

Nesta perspectiva, para Benecke (1990), o conflito de interesses entre o gestor e os associados é explicitado pela forma como é conduzida a gestão da cooperativa ${ }^{5}$. Se os associados não dão instruções corretas ao gestor sobre como gerir o empreendimento, podem haver problemas como: os associados, considerados donos e usuários da cooperativa, podem atuar segundo o que consideram favorável para eles, sem relação com o determinado pelos gestores da cooperativa. Verifica-se, ainda, que a deficiente retroalimentação de informações e de comunicação tem dificultado também o fluxo de informações das cooperativas singulares com as centrais. Além das inúmeras mudanças no mercado, cada vez mais marcado pela competição, as cooperativas estão sendo pressionadas a se unirem a outras, a fim de manterem e/ou expandirem sua participação nos negócios, formando em conjunto uma organização de segundo grau, denominada central. Dessa forma, a busca por maior eficiência e eficácia é que tem provocado a predominância de estruturas verticalizadas de produção (MACEDO et al., 2013; SOUSA et al., 2014).

Neste sentido, Gimenes (2004) salienta que o cenário da atual economia mundial apresenta-se para as cooperativas sob a forma de uma permanente contradição, qual seja, a de manter uma empresa competitiva, capaz de enfrentar

5. Não se pretende entrar na discussão entre propriedade e decisão de gestão, nos moldes apresentados por Costa, Chaddad e Azevedo (2012), priorizando-se a discussão do processo de comunicação entre cooperados e gestores de cooperativa. 
multinacionais de grande porte que atuam nos mesmos mercados e, concomitantemente, atender às necessidades dos seus associados, mas nem sempre conseguindo fazer as duas coisas eficientemente.

Formam-se, assim, estruturas verticalizadas, que permitiriam, a priori, eficiências de escala e de escopo, em que as decisões nas organizações superiores (cooperativa central) estão sustentadas por instâncias de decisão também das bases (cooperativas singulares filiadas à central e seus associados). Geralmente, os critérios de decisão das centrais requerem complexos conhecimentos sobre o funcionamento do sistema agroindustrial, enquanto o conhecimento das cooperativas singulares e produtores está focado nas questóes atinentes à produção primária (MACEDO et al., 2013). Assim, existem dois raciocínios distintos que devem ser harmonizados, o global e o local. Ou melhor, o da produção industrial e da produção primária, para o qual a comunicação passa a ter papel fundamental, como podem ser verificados na fundamentação de Macedo et al. (2013) e Sousa et al. (2014) como supracitado.

Desse modo, a cooperativa central precisa gerir economicamente seus negócios seguindo as demandas do sistema agroindustrial, bem como viabilizando de forma adequada à gestão social, com consulta, participação e decisão junto ao quadro de associados. O fim seria o bem-estar do produtor cooperado. No entanto, em estudos como o de Macedo et al. (2013), observa-se na prática a predominância de interesses econômicos da central sobre os dos associados, acerca da indústria e do mercado de seus produtos, assim, pareceria que a central se converte num fim em si mesma.

Geralmente, a central gerencia uma agroindústria sofisticada, que concorre no mercado com as principais multinacionais do segmento, o que demanda não só capital, mas também planejar estratégias globais, decisões bem projetadas e, principalmente, de produtores que forneçam matéria-prima de qualidade e nas condições que a central cooperativa necessita para atender seus clientes, mercado cada vez mais exigente e em transformação. Porém, os produtores se relacionam com as cooperativas singulares e não diretamente com a central, o que exige delas um papel essencial nessa articulação, com especial atenção ao processo de transmissão das mensagens.

Desse modo, a comunicação cumpre um papel essencial na articulação dos diferentes níveis da organização para que o modelo Central-Singular atue de forma articulada e não concorra por recursos ou se enfrentem diretamente, tirando a potencialidade competitiva da integração vertical cooperativa. Neste contexto, o objetivo do estudo é analisar a comunicação organizacional na articulação agroindustrial entre uma cooperativa central, suas cooperativas singulares e cooperados.

\section{A comunicação nas organizações e suas perspectivas teóricas}

As organizações, privadas ou públicas, funcionam como parte integrante da sociedade. A forma que elas encontraram para informar e se relacionar com a sociedade, dando respostas exigidas pelos indivíduos aos seus anseios, é a comunicação (REGO, 2000). Assim, as organizações necessitam conhecer uma forma própria de se comunicar com seus públicos de interesse.

Em virtude da natureza complexa e multidisciplinar do processo comunicacional, o conceito de comunicação organizacional é difícil de ser definido devido aos seus múltiplos significados (LITTLEJOHN, 1998). Para confirmar esta assertiva, os autores Putnam, Phillips e Chapman (2004) descrevem as diversas equiparações que tanto os teóricos clássicos quanto os teóricos contemporâneos remetem ao termo comunicação organizacional (Quadro 01). Chegam à conclusão de que o conceito de comunicação é uma espécie de "coringa", porque está ligado à maioria dos tópicos sobre os estudos organizacionais. 
Quadro 1. Comparação do termo "comunicação organizacional" definida pelos teóricos clássicos e contemporâneos

\begin{tabular}{|l|l|l|l|}
\hline \multicolumn{1}{|c|}{ Teóricos Clássicos } & \multicolumn{1}{|c|}{ Comparação } & \multicolumn{1}{c|}{ Teóricos Contemporâneos } & \multicolumn{1}{c|}{ Comparação } \\
\hline Weber (1947) & $\begin{array}{l}\text { Documentos escritos e autoridade de } \\
\text { comando. }\end{array}$ & Galbraith (1973) & $\begin{array}{l}\text { Processamento da infor- } \\
\text { mação. }\end{array}$ \\
\hline Taylor (1947) & $\begin{array}{l}\text { Fluxo ascendente das mensagens e ato } \\
\text { de persuadir os trabalhadores. }\end{array}$ & $\begin{array}{l}\text { Rogers e Kincaid (1981); Tichy e } \\
\text { Fombrun (1979) }\end{array}$ & Redes sociais. \\
\hline Fayol (1949) & Fluxo horizontal de informação. & Hage (1974) & Coordenação. \\
\hline Roethlisberger (1941) & Comunicação informal e ouvir. & Likert (1967); Miller e Monge (1986) & Participação. \\
\hline Follet (1941) & Feedback e comportamento circular. & & \\
\hline Simon (1957) & Premissas de decisão. & & \\
\hline Barnard (1968) & Canais formais de comunicação. & & \\
\hline
\end{tabular}

Fonte: Adaptado de Putnam, Phillips e Chapman (2004).

Neste contexto, verifica-se que a comunicação exerce papel essencial nas organizações, pois é inerente à natureza das organizações e vice-versa. Atribui-se a isso o aumento das complexas relações e dinâmicas organizacionais, a necessidade de incorporar maior importância estratégica à comunicação como forma de se preocupar com o coletivo. Assim, a intensificação das práticas comunicacionais permite aprimorar os benefícios das diferentes áreas e públicos que compõem a estrutura organizacional.

É sob os diversos ângulos que as teorias da comunicação organizacional tentam explicar a importância do processo de comunicação na sociedade, embora sem invalidar uma à outra. Elas são condizentes com as perspectivas das teorias da comunicação organizacional que abordam as diversas relações entre fonte e receptor que resultam em diferentes maneiras de transferir mensagens para uma possível compreensão e produção de significado.

Neher (1997) classifica as teorias da comunicação organizacional em cinco perspectivas
(Quadro 2): retórica, de transmissão, psicológica, interacionista e transacional. Este agrupamento levou em conta as especificidades de cada teoria, determinado pelos elementos e variáveis considerados importantes para tal estudo.

A primeira teoria sistematizada sobre a comunicação foi a perspectiva retórica, desenvolvida pelos antigos gregos que aclamavam serem capazes de ensinar a arte do discurso persuasivo. Aristóteles, precursor dos estudos sobre a comunicação humana, descreveu em sua obra "Arte Retórica", a maneira de se exprimir, de se fazer discursos e ser eloquente, porque, no passado, o discurso público era o meio primordial de persuasão e comunicação.

Neste contexto, Aristóteles creditava na comunicação os possíveis meios para concluir a persuasão. Identificou três componentes básicos da comunicação humana (a pessoa que fala, o que diz e a pessoa que ouve), propondo um modelo simples a partir desses elementos no processo de comunicação. O modelo de comunicação criado por Shannon e Weaver em 1949 pro-

Quadro 2. Relação das perspectivas teóricas da comunicação

\begin{tabular}{|l|l|}
\hline \multicolumn{1}{|c|}{ Perspectivas teóricas } & \multicolumn{1}{c|}{ Ênfase dos estudos } \\
\hline Perspectiva retórica & $\begin{array}{l}\text { Mensagens da organização, estratégias de persuasão empregadas nestas mensagens, propósitos } \\
\text { pretendidos para a comunicação. }\end{array}$ \\
\hline Perspectiva de transmissão & Redes de comunicação, canal, codificação e decodificação, direção dos fluxos de comunicação. \\
\hline Perspectiva psicológica & Comunicação interpessoal, filtros conceituais individuais como atitudes, crenças e valores. \\
\hline Perspectiva interacionista & Foco na sociedade, eu e mente; desenvolvimento em grupo do eu, papéis. \\
\hline Perspectiva transacional & Padrão (sistema) de trocas entre duas pessoas, relacionamentos diádicos. \\
\hline
\end{tabular}

Fonte: Adaptado de Neher (1997). 
curou garantir que a transmissão da mensagem de uma fonte para o destinatário fosse reproduzida com alta fidelidade, em razão dos possíveis ruídos ou interferências no canal ${ }^{6}$ de comunicação usado para a transmissão (BYERS, 1997). Este é o modelo mais básico e conhecido da comunicação, denominado Comunicação como Ação, que caracteriza a chamada comunicação de mão única, linear e sequencial, não existindo feedback.

$\mathrm{Na}$ perspectiva de transmissão, o foco é no fluxo de comunicação, através do movimento da mensagem utilizando pelo menos um canal. Desse modo, a comunicação não estará concluída enquanto o receptor não tiver interpretado a mensagem do fluxo de informação.

Quanto a esta perspectiva, são enfatizados a fidelidade, a informação, a codificação e decodificação, a capacidade do canal, o ruído, a redundância e o feedback. Este último, também conhecido como retroalimentação, é outra ideia importante adquirida por esse modelo que permite que as mensagens enviadas voltem para a fonte, indicando a qualidade da mensagem que transitou no processo de transmissão da informação (BYERS, 1997).

A respeito das organizações, nesta perspectiva teórica, Neher (1997) explana que esta abordagem assume

que a organização pode projetar um sistema ou estrutura (canais de comunicação) para facilitar a fidelidade de sua comunicação. A atenção é dirigida para a melhoria da transmissão de mensagens através dos canais, sem muita preocupação, necessariamente, com o conteúdo destas mensagens (NEHER, 1997, p. 46).

Já a perspectiva psicológica enfatiza as estruturas cognitivas dos indivíduos envolvidos no processo de comunicação, isto é, utiliza-se da

6. O modelo hierárquico de riqueza dos canais apresentado por Robbins (2002) aponta a conversa face a face como o canal mais rico, eficaz e rápido de se transmitir as informações. Por outro lado, as mídias escritas impessoais, como folhetos, boletins e relatórios em geral, são os canais mais pobres. comunicação para analisar os processos interpretativos do receptor. Pinho (2006) esclarece que, para entender como funciona este processo, é preciso analisar as atitudes, crenças, necessidades psicológicas, valores e outros constructos mentais dos indivíduos para a compreensão dos efeitos da comunicação, tendo em vista que o foco passa a ser mais no indivíduo do que nos canais ou no processo de transmissão propriamente dito, por esta teoria ter se originado na Escola de Relações Humanas.

A perspectiva interacionista tem o foco no grupo, nas redes sociais, na sociedade e na cultura. Com uma orientação sociológica, esta teoria estabelece que a comunicação ocorre nas interações sociais com outras pessoas, não existindo uma única verdade, pois a partir das interações entre grupos é que eles se juntam ou constroem sua própria realidade e o modo de interpretá-la (PINHO, 2006).

No modelo de Comunicação como Interação, a comunicação circula entre emissor e receptor, os quais podem adaptar ou ajustar suas mensagens por meio da retroalimentação. Com a inclusão do feedback, Byers (1997) explica que o modelo torna-se de mão dupla, pois a circularidade do processo leva à interação, que é mais do que uma simples ação linear. Embora Byers (1997) acredite que o modelo não está perfeitamente completo, uma vez que a interação não transforma a natureza estática do evento, ou seja, o emissor e o receptor não trocam de papéis.

Pautada por um caráter participativo, em que o objetivo principal é o homem e suas relações com o ambiente, esta corrente surgiu a partir das abordagens da Escola Funcionalista, criticada por Freire (1983) quando denominou os modelos clássicos da comunicação de vertical, por ser antidemocrática, voltada para beneficiar o iniciador do processo - a fonte.

A eficácia da abordagem interacionista se completa quando há diálogo. Ou seja, completa quando há interação entre o emissor, a mensagem, o canal e o receptor, à medida que as pessoas discutem, internalizam e selecionam os conteúdos conforme suas necessidades, objetivos 
e realidade. A perspectiva interacionista, segundo Pinho (2006), concebe os grupos como um canal para desenvolver a compreensão dos processos organizacionais, dos valores e da realidade, além de favorecer o estudo das culturas organizacionais, do seu desenvolvimento, dos sistemas de valores e das possíveis mudanças.

A última perspectiva apresentada é o modelo de Comunicação como Transação, concebido por Dean Barnlund. Diferente das demais abordagens, linear e circular, o ponto central é que as pessoas são simultaneamente e continuamente, emissoras e receptoras. Byers (1997) explana que o processo de transação é constituído de três princípios:

- Os participantes são, contínua e simultaneamente, emissores e receptores. Isto implica que os interlocutores, mesmo quando não estão se expressando oralmente ou se movendo, estarão, ainda assim, enviando mensagens;

- A comunicação tem passado, presente e futuro. Os fatos passados podem influenciar a forma como os interlocutores codificam ou decodificam a atual mensagem, da mesma maneira que o futuro;

- Os participantes desempenham papéis que determinam, de certa forma, a organização e a interpretação das mensagens.

Assim, verifica-se que os objetivos individuais são menos importantes do que o estabelecimento de um novo consenso ou compreensão, cujos padrões de intercâmbios comunicativos oferecem uma nova forma de descrever e explicar os problemas e possíveis rupturas na comunicação relacional.

Dessa forma, apresentando as diversas perspectivas conceituais, se fez a tentativa de interpretar e explicar a natureza complexa e abrangente do conceito de comunicação organizacional resultando em teorias distintas, cada uma evidenciando um determinado aspecto em detrimento de outros, mas com suas particularidades (PINHO, 2006) que, comumente, tentam explicar suas particularidades na transmissão de mensagens.

\section{A comunicação na gestão cooperativa}

Os estudos organizacionais revelam a existência de várias formas de gestão e participação no âmbito das organizações. As cooperativas, desde os tempos de cooperação dos Pioneiros de Rochdale, postulam se organizar baseadas na autogestão, na autonomia e na democracia participativa, embora isso nem sempre seja plenamente exercido por todos os ramos do cooperativismo, devido a interesses e necessidades específicas.

Neste sentido, as cooperativas representam um conjunto de atividades peculiares dentro do sistema econômico-financeiro, com características próprias. Diferenciada por sua dupla natureza, como apresentado na Figura 1, a sociedade cooperativa é desafiada a atingir em sua gestão, ao mesmo tempo, objetivos de ordem econômica e social, o que a torna, a priori, mais complexa e distinta de outras formas de organização. No caso da gestão empresarial, a sua finalidade é gerir os interesses e incentivos econômicos dos associados do empreendimento coletivo, além de se preocupar com questões estratégicas da administração, tais como os aspectos financeiros, de produção, marketing, entre outros. Por outra parte, a gestão social está voltada para o relacionamento da cooperativa com os associados, como forma de promover sua participação em processos decisórios, bem como qualificá-los para tal, além de assegurar espaços nas instâncias participativas. Além disso, com a cooperação como base de suas práticas, a eficiente gestão econômica e social é o que garantiria à sociedade cooperativa cumprir com o seu imperativo democrático, base pela qual se diferencia das demais organizações econômicas.

Orientada a privilegiar a democracia, a organização cooperativa é desafiada a divulgar seus valores e princípios junto ao público envolvido, que de alguma forma se relaciona com ela e, especificamente, aos seus associados. Ressalta-se que este tipo de organização apresenta características diferenciadas e intrínsecas pautadas por valores e princípios que são de natureza própria, mas não exclusivos delas. Pois, coincidentemente, a demo- 
Figura 1. Dupla natureza cooperativa

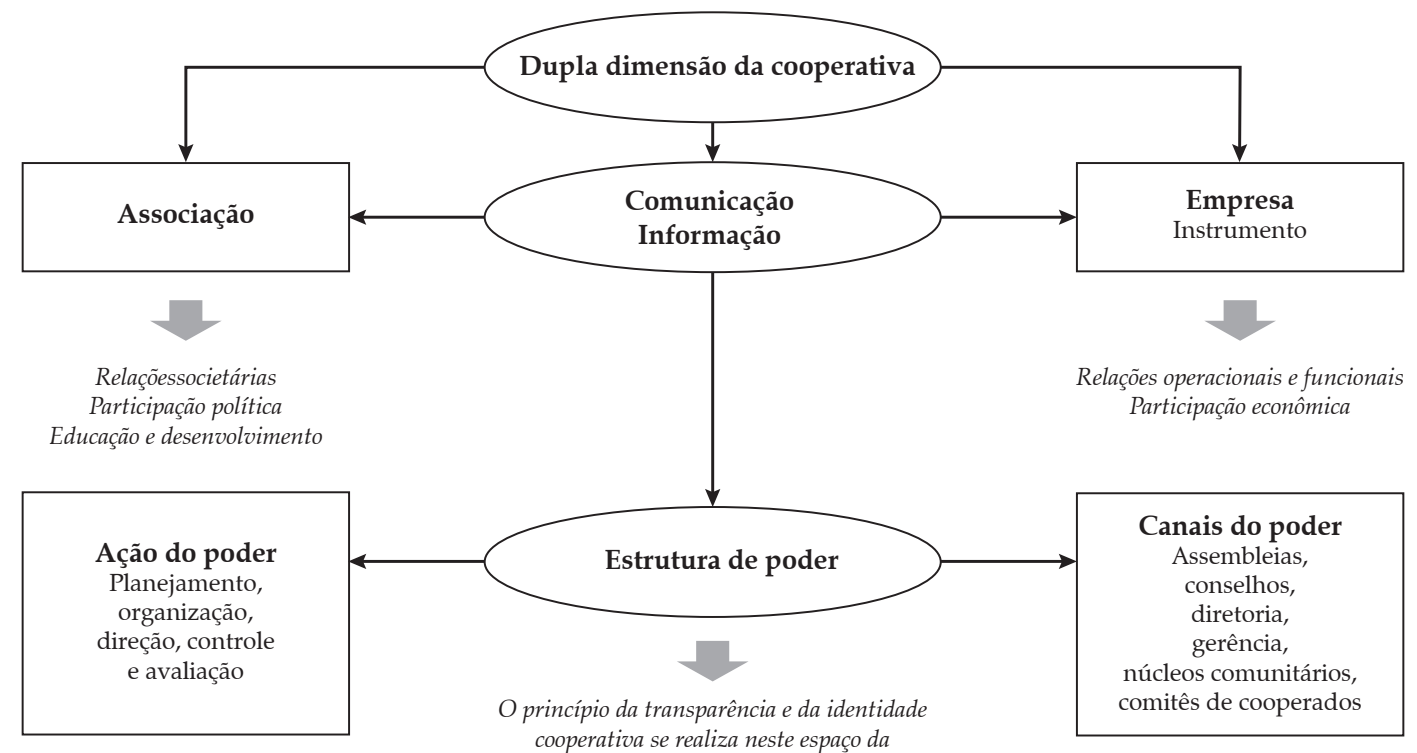
prática cooperativa

Fonte: Valadares (2009).

cracia em uma determinada sociedade pode levar a valorizar mais essa forma organizacional.

Para ilustrar a realidade da gestão das cooperativas, o estudo de Oliveira (2006) descreve, no Quadro 3, os seus principais problemas e consequências. A partir dos elementos citados, pode-se inferir que esses problemas são de ordens diversas, diferenciados de acordo com tipologia, estrutura e realidade de cada cooperativa.

Neste e em outros estudos, a percepção da falta ou esquecimento da educação cooperativista por parte dos cooperados é ressaltado como um dos principais problemas encontrados nas cooperativas e de todo o sistema cooperativista (RICCIARDI e JENKINS, 2000; SCHENEIDER, 2003; AMODEO, 2006; BIALOSKORSKI NETO, 2006; VALADARES, 2009; FERREIRA et al., 2013), bem como é confirmado que as cooperativas não apresentam modelos adequados de gestão e tampouco há cooperação entre elas (BIALOSKORSKI NETO, 2000; CHADDAD, 2000; CRÚZIO, 2006).

De maneira prática, Oliveira (2006) aponta alternativas para a solução dos problemas do cooperativismo, entre eles, os supracitados, por meio

Quadro 3. Principais problemas e sua consequência na gestão das cooperativas

\begin{tabular}{|l|l|}
\hline \multicolumn{1}{|c|}{ Problema } & \multicolumn{1}{|c|}{ Consequência } \\
\hline $\begin{array}{l}\text { 1. Falta ou esquecimento da educação cooperativista por parte } \\
\text { dos cooperados. }\end{array}$ & Consolida a ruptura do cooperado com a cooperativa. \\
\hline 2. Não apresentação de adequados modelos de gestão. & Falta de aplicação de modernos instrumentos administrativos. \\
\hline $\begin{array}{l}\text { 3. Falta de cooperação entre as cooperativas quanto a suas ativi- } \\
\text { dades e seus negócios. }\end{array}$ & Prejudica a gestão e o processo evolutivo das cooperativas. \\
\hline $\begin{array}{l}\text { 4. Aplicação de modelos de gestão centralizados. } \\
\text { Consolida uma administração presidencialista que pode levar } \\
\text { quados. }\end{array}$ \\
\hline $\begin{array}{l}\text { 5. Não saber trabalhar, adequadamente, com a concorrência. } \\
\text { f. Confusão entre "propriedade de gestão" e "propriedade da da } \\
\text { cooperativa". }\end{array}$ & $\begin{array}{l}\text { Extinção de várias cooperativas que serão aniquiladas pelos no- } \\
\text { vos e fortes concorrentes que estão se consolidando no mercado. } \\
\text { do entre diferentes pessoas. }\end{array}$ \\
\hline
\end{tabular}

Fonte: Adaptado de Oliveira (2006). 
de seis ações, aparentemente indispensáveis à gestão cooperativa. São elas:

1. Cadastro dos cooperados;

2. Desenvolvimento de núcleos de cooperados sustentados por agentes;

3. Desenvolvimento e disponibilização de informações adequadas e atualizadas para os cooperados;

4. Desenvolvimento de um plano estratégico com adequados indicadores de desempenho;

5. Estabelecimento de classes de cooperados com benefícios e restrições específicas, de acordo com o nível de interação dos cooperados com a cooperativa;

6. Foco das ações nos jovens e filhos de cooperados.

Para o autor, essas ações devem estar mais bem estruturadas em uma moderna gestão cooperativa, bem como de acordo com sua estrutura organizacional, principalmente pela intermediação dos meios de comunicação que ela deveria utilizar na interação com seus diversos públicos. Ou seja, se a cooperativa tem uma significativa produção de escala, teria que ter uma estrutura comunicacional para diminuir os ruídos entre direção, cooperados e funcionários.

Para que isso se concretize, a cooperativa necessita estar gerida de tal modo que as gestões social e econômica sejam complementares e igualmente promovidas para cumprir os seus objetivos. Dessa forma, a educação cooperativista tem exatamente o papel de atuar simultaneamente em ambas as formas de gestão, desenvolvendo processos de capacitação que sustentem e promovam uma adequada gestão cooperativa.

O desenvolvimento de uma cooperativa, segundo Valadares (2009), está diretamente relacionado ao desenvolvimento da comunicação e da educação cooperativista, isto é, da gestão social cooperativa. Detalhadamente explica que

a inexistência de um bom e eficiente sistema de educação e comunicação entre associados, dirigentes e funcionários, voltado aos interesses da comunidade cooperativa, prejudica o associado na sua função de dono e usuário da cooperativa, que passa a distanciar-se progressivamente de sua função primordial, que é a prestação de serviços aos associados. Transforma-se numa empresa ineficiente, por não conseguir o suficiente grau de adesão dos associados, carentes das informações necessárias para se comprometerem mais com sua organização; ou transforma-se numa empresa eficiente, progressista, mas apenas uma empresa como outra qualquer, valorizando apenas a dimensão econômica e relegando a dimensão social à segundo ou terceiro plano (VALADARES, 2009, p. 20).

Dentro dessa conformidade, o referido autor especifica que, em especial no caso de cooperativas agropecuárias, a comunicação e a educação podem ser operacionalizadas, sobretudo, por meio da Organização do Quadro Social (OQS). A OQS envolve a implementação de comitês educativos, também conhecidos como núcleos, conselhos representativos ou comissões locais, ambiente onde os associados se reúnem de forma periódica e sistemática, e que têm como objetivo ser uma "ponte de ligação" entre o quadro social e o quadro dirigente da organização cooperativa. Este trabalho permite que os dirigentes interajam mais com os cooperados, discutindo conjuntamente seus planos e propostas de trabalho, seus objetivos e metas, as informações sobre a realidade econômico-financeira da cooperativa e dos associados, as tendências dos mercados, para que, juntos, possam encontrar a solução dos problemas tanto da cooperativa quanto dos cooperados, conseguindo, desta forma, benefícios para ambos. Além disso, a OQS, assim como representa uma significativa ferramenta de gestão social, também é lócus para o desenvolvimento de trabalhos de educação cooperativista, o que permitiria sustentar uma efetiva comunicação e capacitação, adequadas à realidade de cada cooperativa e dos seus associados.

Um dos principais objetivos da OQS é estruturar um espaço de poder na cooperativa, viabilizando a participação democrática do maior número possível de associados na gestão do 
empreendimento cooperativo. Esta instância de participação possibilita maior envolvimento dos cooperados com a vida institucional das cooperativas, aumentando o seu poder na mesma, já que as estruturas formais de participação como Assembleia Geral, Conselho de Administração e Conselho Fiscal mostram-se ineficientes ou inadequados, dada a formalidade que geralmente se reveste a participação (VALADARES, 2003).

Para ilustrar essa discussão, o estudo conduzido por Macedo et al. (2011) sobre o papel da OQS na articulação da relação associado x cooperativa singular $\mathrm{x}$ cooperativa central ao longo da cadeia produtiva leiteira aponta que os produtores que participam das reuniões dos comitês educativos, em média, possuem maior produtividade litros/vaca/dia quando comparados aos que não participam. Isso seria um indício da vantagem da participação dos membros nos núcleos, por receberem mais informações técnicas nas reuniões, o que teria impacto direto na sua produtividade, visto que, com mais informações e capacitação, o planejamento e a execução da produção tornam-se mais fáceis e eficientes. Outro resultado foi que as pessoas que participavam recebiam mais informações sobre a cooperativa, as produções e os mercados, que aqueles que não participavam. Atualmente, a informação é considerada um dos mais importantes recursos da organização produtiva, essencial ativo dos produtores rurais para que eles consigam entender as exigências do mercado e conhecer as novas tecnologias produtivas disponíveis e acessíveis para atender a demanda, ou seja, é o processo de comunicação realizado de forma eficiente e atrelado à educação cooperativista, uma das bases de funcionamento da OQS.

Schneider (1982) vai além ao afirmar que, se a informação direcionada aos cooperados pelos dirigentes for muito limitada, eles tenderão a ignorar até que ponto os dirigentes realmente visam ou não à sua promoção econômica e social, abrindo os canais para o receio e a desconfiança, o que diminui o grau de adesão.

Zylbersztajn (2002) aponta que, quando se tratar de organizações cooperativas, a informação direcionada aos associados toma ainda mais relevância, por ser considerado o ativo mais importante e específico da organização. Desse modo, percebe-se que a informação gera potencialmente um ato de comunicação. Ou seja, o ato de comunicar é realizado no sentido de tornar algo comum a alguém ou a um grupo e isso, por si só, já é vital para a sobrevivência de qualquer organização, uma vez que a comunicação é que mantém e sustenta os relacionamentos no ambiente organizacional.

Assim, é necessário que as cooperativas desenvolvam processos dinâmicos e interativos de comunicação, os quais não seriam possíveis sem a existência de instâncias, pessoas e/ou setores específicos na organização que tenham essa responsabilidade dentre suas funções na cooperativa. De acordo com Rego (2000), a proposta de instituir o setor de comunicação em uma organização está relacionada com a necessidade de assegurar eficácia aos atos comunicativos na empresa, reduzindo-se, ao máximo, os riscos por ocasião da implantação de sistemas de comunicação.

Para Schmitz (2003), as cooperativas necessitam de programas específicos de comunicação que favoreçam a articulação interna e externa de seus públicos e que estabeleçam uma dimensão apropriada para divulgar e incorporar os valores e princípios que as perpassam, pois as ações organizadas devem fazer parte de um programa permanente, com iniciativas e objetivos claramente definidos, para fortalecer as ações de educação cooperativista.

A ação da gestão cooperativa exige mecanismos formais de comunicação, conforme apresenta Frantz (1983), por se tratar de um procedimento inerente ao processo de formação de cooperativas. Schneider (2003) entende que é justamente pelo aumento do fluxo de informações e de atividades educativas na perspectiva da ajuda mútua que se obtém um bom e eficiente relacionamento entre a cooperativa e os associados ou entre cooperativas.

Dessa forma, percebe-se a necessidade de organizar os fluxos de informação numa pers- 
pectiva relacional entre dirigentes e associados e, também, outras relações existentes no ambiente cooperativo, como forma de proporcionar uma comunicação do tipo simétrica. Na visão de Pasquali (1973, p. 104), a comunicação autêntica é aquela que "se assenta num esquema de relações simétricas, em uma paridade de condições entre emissor e receptor, na possibilidade de ouvir o outro e ser ouvido, como possibilidade mútua de entender-se".

Busca-se, então, nas cooperativas uma comunicação de relações simétricas que proporcione melhor contato e intercâmbio entre seus públicos, uma vez que esta organização permite em sua estrutura específica - ambiente de tomada de decisão coletiva - uma relação mais participativa e dialógica.

Assim, um eficiente processo de comunicação contribuiria para que a gestão social fosse economicamente relevante na organização cooperativa. Por isso, Matos (2009) salienta que as organizações que podem se comunicar mais rapidamente numa rede social têm mais vantagens organizacionais. A autora acrescenta ainda que as redes sociais e a comunicação que articula as conversações, face a face ou mediadas, são de suma importância para que o "empreender juntos" seja possível. No mesmo sentido, Valentinov (2004) também considera que, quanto maior a eficácia dos processos de comunicação e interação, maior é o retorno para os membros associados.

Isto posto, compreende-se que as gestões social e empresarial precisam ser reforçadas pela educação cooperativista, razão pela qual é necessário priorizar importantes mecanismos de comunicação interna na cooperativa e com os associados, bem como reforçar a gestão interna do poder para que ocorra o alcance da aprendizagem conjunta. Busca-se, então, nas cooperativas, uma comunicação de relações simétricas que proporcione melhor contato e intercâmbio com os públicos envolvidos, uma vez que esta organização requer, em sua estrutura, uma relação mais participativa e dialógica. Logo, é função da comunicação dar suporte aos trabalhos de educação cooperativista.

\section{Metodologia}

Foi realizado um estudo de caso de um modelo federado de cooperativas (no qual cooperativas singulares são filiadas a uma cooperativa central) de leite, utilizando-se de fontes primárias, com o apoio da técnica de entrevista semiestruturada (série de questões de pesquisa a serem abordadas ao longo da entrevista), além de fontes secundárias. $\mathrm{O}$ estudo foi qualitativo de caráter exploratório-descritivo. As fontes primárias foram obtidas por meio de dois grupos de informantes: os dirigentes e os profissionais do setor de comunicação da cooperativa central e das cooperativas singulares. A amostra das cooperativas singulares filiadas à cooperativa central foi de caráter intencional, pois, das 29 cooperativas sócias da central localizadas em Minas Gerais, foram selecionadas 10 cooperativas que tinham produção de leite acima de 100.000 litros/dia. Conforme avaliado por Oliveira (2006) e Sousa et al. (2014), cooperativas de maior porte de produção requerem melhor estrutura organizacional, o que permitiria contar com um setor próprio de comunicação, uma vez que não importaria para este estudo uma cooperativa que não tivesse uma política comunicacional estruturada ou em fase de estruturação. Desse modo, todas as cooperativas singulares selecionadas desta amostra possuíam ações de comunicação vinculadas a um setor ou tinham seu próprio setor, apesar de termos encontrado apenas dois jornalistas contratados, ou seja, duas cooperativas que contrataram profissionais de comunicação apesar de as demais realizarem atividades nesta área.

Como forma de manter sigilo nos dados informados, não serão identificadas as cooperativas singulares selecionadas, nem tampouco a central. Dentre as dez cooperativas singulares pesquisadas, só existiam dois (2) jornalistas nos cargos de comunicador, os quais, somados aos presidentes/representantes (10) e aos comunicadores da central (2), totalizam um total de 14 entrevistas realizadas neste estudo. Para garantir que a identidade dos entrevistados não fosse revelada foi feita a opção de identificar os presi- 
Quadro 4. Perfil dos Informantes

\begin{tabular}{|c|l|c|c|}
\hline $\begin{array}{c}\text { Identificação do } \\
\text { Informante }\end{array}$ & \multicolumn{1}{|c|}{ Cargo do informante } & Local da entrevista & $\begin{array}{c}\text { Observações da } \\
\text { cooperativa }\end{array}$ \\
\hline A & $\begin{array}{l}\text { Presidente de Cooperativa Singular e Conselheiro Fiscal da Cen- } \\
\text { tral }\end{array}$ & Sede da cooperativa & Tem OQS \\
\hline A-1 & Assessor de comunicação & Sede da cooperativa & \\
\hline B & $\begin{array}{l}\text { Presidente de Cooperativa Singular e Conselheiro Administra- } \\
\text { tivo da Central }\end{array}$ & Sede da cooperativa & Gestão Virtual \\
\hline C & Presidente de Cooperativa Singular & Sede da cooperativa & Tem OQS \\
\hline D & $\begin{array}{l}\text { Presidente de Cooperativa Singular e Conselheiro Administra- } \\
\text { tivo da Central }\end{array}$ & Sede da cooperativa & Tem OQS \\
\hline E & Presidente de Cooperativa Singular & Sede da cooperativa & \\
\hline E-1 & Gerente de Marketing & Sede da cooperativa & \\
\hline F & Presidente de Cooperativa Singular & Sede da cooperativa & \\
\hline G-1 & $\begin{array}{l}\text { Coordenador da assessoria de relacionamento com o produtor } \\
\text { da Central }\end{array}$ & Sede da cooperativa & \\
\hline G-2 & $\begin{array}{l}\text { Jornalista da assessoria de relacionamento com o produtor da } \\
\text { Central }\end{array}$ & Sede da cooperativa & \\
\hline H & Presidente de Cooperativa Singular & Seminário & Seminário \\
\hline I & Presidente de Cooperativa Singular & Seminário & Sem OQS \\
\hline J & Presidente de Cooperativa Singular & Tem OQS \\
\hline K & Presidente de Cooperativa Singular & \\
\hline
\end{tabular}

Fonte: Dados da pesquisa (2011).

dentes de cooperativas com letras e os comunicadores, com letras similares às das respectivas cooperativas, acrescido de números. Assim, no decorrer do estudo, são feitas referências às dez cooperativas singulares (A, B, C, D, E, F, H, I, J e $\mathrm{K})$, à cooperativa central $(\mathrm{G})$ e aos comunicadores (A-1, E-2, G-1 e G-2).

Para a coleta de dados, realizada em 2011, foi utilizado um roteiro com 13 perguntas abertas que orientaram as entrevistas semiestruturadas ${ }^{7}$ realizadas na sede de sete cooperativas singulares e na Central, e nas demais (4), foram realizadas num seminário cooperativista onde participavam os representantes das cooperativas singulares na central. A escolha desta técnica qualitativa (entrevista semiestruturada) ocorre devido à maior facilidade de obter dados mais precisos com a presença do entrevistador, como argumenta Babbie (1999), ao explicar que a entrevista reduz

7. Nas entrevistas semiestruturadas, no geral, as perguntas são abertas e podem ser respondidas dentro de uma conversação informal, indo além do programado no roteiro de perguntas. É uma forma de explorar mais amplamente uma questão (BABBIE, 1999). a incidência de perguntas sem resposta, podendo evitar confusões com as perguntas do roteiro, além de poder observar reações dos entrevistados às perguntas.

O tempo das entrevistas variou entre $20 \mathrm{minu}-$ tos a aproximadamente uma hora de duração, de acordo com o interesse e o volume de informações que cada um dos informantes apresentou ao responder as 13 questões do roteiro, as quais estavam organizadas em dois blocos. O primeiro bloco de perguntas buscava caracterizar e analisar a realidade da comunicação organizacional na cooperativa central. O segundo bloco objetivou entender como se dá a articulação agroindustrial na integração vertical de cooperativas. Para tanto, a entrevista explorou temas afins como os benefícios da associação, facilidades e dificuldades do modelo federado de cooperativas, educação cooperativista e assistência técnica e extensão rural.

Já as fontes secundárias pesquisadas foram as revistas e a home page da cooperativa central e os jornais das cooperativas singulares, além da literatura especializada que deu embasamento ao estudo em questão. 


\section{Resultados e discussão}

Nesta seção, o objetivo é apresentar os resultados da análise da comunicação organizacional em uma cooperativa central de referência no setor lácteo brasileiro com suas cooperativas singulares e os associados.

Em 2008, a partir da transição da última diretoria da central, houve mudanças na estrutura de comunicação, com a criação da assessoria de relacionamento com o produtor, objetivando melhorar os fluxos de comunicação entre a cooperativa central, as cooperativas singulares e os produtores rurais cooperados, por meio da comunicação de massa. A equipe desta assessoria foi composta por cinco profissionais: dois jornalistas, um relações públicas, um agrônomo e um economista, que é o coordenador da referida assessoria.

Conforme o composto da comunicação organizacional integrada, elaborado por Kunsch (2008), a criação de uma assessoria estaria ligada à comunicação institucional, a qual está relacionada à normatização de relações confiantes e reputação positiva com os públicos que se relacionam, especificamente nesta ocasião, os produtores rurais. Além disso, utilizaria as ferramentas comunicacionais para divulgar a missão, valores e princípios que perpassam a organização.

Assim, esta assessoria buscou intensificar a comunicação, que se avaliava como pulverizada, pois pouca informação da central era acessada pelas cooperativas singulares e pelos produtores. Ou seja, era o receptor quem ia à procura da informação. Não existiam informativos, tampouco veículos de comunicação que atendessem suas demandas, interesses e/ou exigências. Os informantes afirmam que as ações partiram do pressuposto da valorização dos princípios que regem as cooperativas singulares no processo de transmissão das informações junto à central. Dessa forma, reconhecia-se a importância das singulares neste processo em função de sua proximidade com o produtor e sua experiência de atuar localmente, pontos que facilitariam alcançar e se relacionar com este público estratégico.

Manifestaram a dificuldade de desenvolver a área de comunicação devido ao grande número de produtores que entregam leite à central visto que, segundo um dos informantes, o sistema possui aproximadamente 8.000 produtores de leite. Esse número é maior que o total de produtores de leite de alguns países exportadores, como o Uruguai, por exemplo, que tem pouco mais da metade dessa quantidade de produtores.

O primeiro passo, antes de iniciar o planejamento estratégico da assessoria de relacionamento com o produtor, foi dado em 2008, quando a central encomendou a realização de uma pesquisa para conhecer o perfil de seus produtores e, assim, poder utilizar adequadamente os diferentes meios de comunicação, massivos e dirigidos, que lhes possibilitassem difundir as suas propostas e realizações.

A amostragem da pesquisa feita pela central foi de 5.000 produtores associados, perfazendo $62,5 \%$ do total. Os entrevistados afirmam que esta foi considerada uma das maiores pesquisas realizadas com produtores rurais no País. Parte desses dados foi disponibilizada, como mostra o Quadro 5 a seguir.

Quadro 5. Informações sobre acesso à informação dos produtores da cooperativa central

\begin{tabular}{|c|c|c|}
\hline Informação & Sim & Não \\
\hline Hábito de leitura & $56 \%$ & $44 \%$ \\
\hline Possui computador na propriedade & $30 \%$ & $70 \%$ \\
\hline Acesso da internet na propriedade & $8 \%$ & $92 \%$ \\
\hline
\end{tabular}

Fonte: Dados da pesquisa (2011). 
Quadro 6. Canais de comunicação de responsabilidade da "assessoria de relacionamento com o produtor" da cooperativa central

\begin{tabular}{|l|l|}
\hline \multicolumn{1}{|c|}{ Tipos de canais } & \multicolumn{1}{c|}{ Produtos de comunicação da "assessoria de relacionamento com o produtor" } \\
\hline Escritos ou impressos & Revista Produtor, Radar Técnico, Matérias no Caderno Agropecuário do Jornal Estado de Minas, Circulares. \\
\hline Encontros e entrevistas & Programa Nossa Fábrica, Seminário interno de comunicação. \\
\hline Reuniões de grupo & Reunião com os presidentes das cooperativas singulares. \\
\hline Mídia & Boletim Produtor online, Totem de tecnologias da Embrapa, Vídeos do Agrotube, Portal do Produtor. \\
\hline
\end{tabular}

Fonte: Dados da pesquisa (2011).

O primeiro dado revela que quase a metade dos produtores não tem o hábito da leitura. Esse fato poderia estar atrelado ao nível de formação, em que se verificou que aproximadamente 50\% são analfabetos ou apenas possuem curso primário. Dessa forma, na maioria das vezes, para serem informados, é preciso do auxílio da esposa e/ou filhos para ler os informativos da cooperativa e repassar as informações ao produtor. $\mathrm{Ou}$ seja, a primeira estratégia foi focar na família e não somente no produtor isoladamente. $\mathrm{O}$ baixo percentual de computadores na propriedade também estaria atrelado à mesma razão, o baixo nível de formação, além de possivelmente os produtores terem pouca habilidade para utilizar o computador somado ao desinteresse de usar esta ferramenta de comunicação. Consequentemente, para a cooperativa central poder se utilizar de computadores como instrumento facilitador da comunicação, seriam necessários investimentos neste âmbito para facilitar o acesso dos produtores de leite às tecnologias da informação e comunicação - TICs, com capacitação e financiamentos, a fim de lhes propiciar expansão e melhor aproveitamento dessas tecnologias, como está sendo feito com o Totem de Transferência de Tecnologia, como será explicado mais adiante.

Há poucos produtores com acesso à internet na propriedade rural e que manifestaram precisar estar conectados com as notícias diárias do mercado. Ressalta-se que este dado sobre o acesso à internet restringe-se ao uso na propriedade, não tendo sido considerado que poderia ser possível o acesso dos usuários na casa de outra pessoa, num centro público de acesso gratuito, numa lan house etc.
Como as ferramentas a serem utilizadas na comunicação precisam ser pensadas para atender às especificidades dos públicos, ressalta-se essa primeira característica que deverá ser considerada pelos profissionais da assessoria de relacionamento com o produtor, ao escolher os meios de comunicação a utilizar. Para tanto, pensando nesta realidade, a proposta dos profissionais foi incentivar a leitura com temas lúdicos, pouco texto, muita cor e fotos para poder despertar o interesse. Além disso, ressalta-se que a importância da utilização de específicos e diferentes meios de comunicação se dá para melhor fidelização da mensagem. A síntese dos canais de comunicação utilizada pela assessoria de relacionamento com o produtor está especificada no Quadro 6.

Como podem ser observados no quadro acima, os principais meios utilizados são os escritos/impressos e os de mídia, do tipo descendente. Faz-se necessário lembrar que uma parcela dos associados não tem o hábito de leitura e nem tão pouco acesso à mídia disponibilizada online. No entanto, estes produtos ${ }^{8}$ são coerentes, dados os recursos disponibilizados a esta assessoria pela central, principalmente no que se refere ao número de contratação de profissionais.

O primeiro meio de comunicação editado foi o encarte Produtor, distribuído junto à revista Balde Branco', que também é entregue gratuitamente pela central. Segundo o informante G-1, diante de tal "sucesso de credibilidade" e moti-

8. Vale lembrar que a expressão produtos equivale aos canais de comunicação. No decorrer deste tópico, em vários momentos, estará assim mencionado.

9. Revista de maior circulação do setor lácteo, segundo o informante G-1. 
vado pelo fato de ser um produto de fácil entendimento e com a "cara do produtor", este encarte tornou-se revista em 2010, sendo distribuída por meio das cooperativas singulares, deixando amostras na sede e também podendo ser organizada a entrega desse material na propriedade do produtor.

Posteriormente, se começou com a edição do Boletim Produtor online, enviada mensalmente via e-mail aos produtores cadastrados no site ou em eventos da central. Na mesma linha, foi criada uma newsletter, publicada semanalmente por meio de drops, notas de um a dois parágrafos, sobre assuntos referentes à cooperativa central e às cooperativas singulares. Nesse sentido, um dos participantes da pesquisa assegurou que esses meios de comunicação mencionados são os mais comumente utilizados também para ter acesso às informações do dia a dia proveniente das cooperativas singulares. Observe o relato que segue:

"É aqui que temos maior fluxo de informações das cooperativas, que nos mandam notícias sobre cursos, algum evento que promoveram, investimento em estrutura" (Relato do comunicador G-2).

Nesse sentido, a inclusão desses produtos de comunicação online foi explicada pelo baixo custo de produção e distribuição, e mesmo verificando o baixo número de produtores rurais que acessam a internet, os entrevistados percebem o crescimento no número de usuários no meio rural, evidenciando um canal de comunicação em potencial. Embora, como mencionado, seja também necessário atentar para o fato de que, segundo a pesquisa realizada pela própria central, 92\% dos produtores não tivessem acesso à internet e não dominassem parte dessa tecnologia. Entendem, por outro lado, que os técnicos que trabalham diretamente com esses produtores podem se transformar em divulgadores das informações contidas nesses canais online de comunicação.

Com um conteúdo de caráter mais técnico, foi lançado o "Radar Técnico", sem periodicidade fixa, no qual os temas publicados são aqueles relevantes no momento. Tem como público privilegiado os diretores, técnicos de todas as áreas e os produtores com nível maior de qualificação. Além disso, a central publica uma matéria de duas páginas no Caderno Agropecuário de um jornal de grande circulação nacional que também é distribuído aos produtores. Eventualmente, quando se detecta a necessidade, são distribuídas circulares elaboradas pela diretoria, com abordagens sobre o demonstrativo de quanto o produtor recebeu de sobras e das atualizações do preço do leite no mercado.

A estratégia de distribuição dos produtos de comunicação escritos e impressos, como os supracitados, está baseada na sua entrega junto à Folha do Leite ${ }^{10}$, que o produtor recebe mensalmente na sede da cooperativa.

Aprofundando em direção às novas TICs, a central está implantando, em parceria com a Embrapa Gado de Leite, um sistema de terminais de computadores com o objetivo de organizar e disseminar informações técnicas ao produtor de leite, que é conhecido como "Totem de Tecnologias da Embrapa", parecido com os terminais de check-in de aeroporto, os quais ficarão na sede das cooperativas. Com essa ferramenta, o produtor poderá pesquisar artigos com as mais variadas informações, ter acesso ao Portal da Cooperativa, da Embrapa, entre outros sites afins, além de poder imprimir artigos de interesse técnico e o extrato da Folha do Leite.

A central estabeleceu também uma parceria com a Agrotube, empresa similar ao Youtube, porém com um serviço diferenciado voltado para atender empresas e instituições vinculadas ao agronegócio, que cria vídeos institucionais e os colocam em site próprio. Assim, estão sendo desenvolvidos vídeos institucionais que retratam a história das cooperativas singulares filiadas, que serão disponibilizados na internet. Foi crriado também o "Portal do Produtor", que direciona informações de interesse para os produtores, acrescido de hiperlinks dos conteúdos

10. Folha mensal de pagamento dos produtores fornecedores de leite. 
contidos nos produtos de comunicação supracitados. Observou-se que esta sessão de comunicação com o produtor foi separada do site institucional da cooperativa central, avaliando-se que esta decisão deve-se à criação da assessoria de relacionamento com o produtor, que vem ganhando espaço na gestão da central.

Além desses veículos, foi implementado o programa de encontros "Nossa Fábrica", realizado mensalmente com uma cooperativa singular sorteada, no qual os produtores visitam a fábrica da central, sem nenhum custo, para conhecer o processo desde a chegada do leite até a industrialização. $\mathrm{O}$ encontro se inicia com a recepção do presidente, e depois os convidados assistem a um filme institucional para melhor entender a estrutura gerencial e industrial. Neste caso, trata-se de interações face a face, nas quais o nível de formação dos produtores não seria limitante para o acesso à informação.

Outra forma de comunicação se implementa por meio de seminários internos com os representantes do departamento de comunicação e jornalistas das cooperativas que têm ou estão em fase de implementação de uma política comunicacional. O objetivo é tratar sobre os produtos informativos que foram implantados e os que serão criados pela central, bem como a organização de palestras para mais esclarecimentos sobre temas relevantes da área. A ideia foi criar um espaço de interatividade com este público de interesse a fim de promover sugestões e críticas que possam servir para fortalecer o crescimento da rede de comunicação da central.

A central cooperativa estabeleceu uma assessoria de relacionamento com o produtor, que implementou uma série de ferramentas e canais de comunicação tendentes a fazê-la mais eficiente. Contudo, nota-se que a ligação entre as cooperativas singulares e seus produtores associados, pela proximidade, lhes possibilitaria melhores possibilidades de atendimento de suas necessidades. Assim, embora se reconheça o potencial das ações desenvolvidas pela central, os informantes enfatizam que as cooperativas singulares têm mais possibilidades de se comunicar com os cooperados, identificar e lhes informar sobre questões do seu interesse, sem serem aproveitadas devidamente. Os relatos apresentados pelos informantes G-1 e G-2 caminham nessa direção, como pode ser visualizado abaixo.

“É a Cooperativa Singular que está presente no dia a dia, que tem conversas com mais frequência e que tem o seu próprio jornal para relatar e difundir as informações da localidade" (Relato do comunicador G1).

“Os produtores ficam surpresos em participar da revista e até mesmo ser capa, pois os modelos da revista são os próprios produtores" (Relato do comunicador G2).

“O papel da central não é realizar a educação cooperativista, o papel prioritário é econômico. Quem faz isso é a singular. A central faz a articulação econômico-administrativa para que o produto do cooperado seja competitivo no mercado. A singular assume o papel mais social realizando a fidelização, prestação de assistência técnica, coloca à disposição os insumos a preços melhores, de representação dos associados junto à Central" (Relato do informante K).

Podem ser ressaltados como um ponto forte na política de comunicação da central os seus técnicos extensionistas (agrônomos, zootecnistas, veterinários) como importantes canais de comunicação junto às cooperativas singulares e aos produtores rurais. A cooperativa central possui um dos maiores sistemas privados de prestação de assistência técnica do País, com mais de 60 técnicos, cobrindo a maior parte de sua área de influência. No entanto, foram ouvidos relatos com críticas, assinalando que alguns profissionais passam maior tempo no escritório que no campo, o que seria justificado por ficarem mais focados na área de compra e venda da cooperativa. No entanto, seria preciso estabelecer uma política mais clara para potencializá-los como comunicadores, sobretudo pela proximidade que eles mantêm com o produtor rural, podendo apresentar maior interação e uma comunicação mais simé- 
trica que qualquer sistema de comunicação baseado em tecnologias de massa.

Constatou-se que quem realiza as atividades de educação cooperativista são as cooperativas singulares, deixando à central a articulação dos temas econômicos e administrativos. Isso fica claro no conteúdo das informações divulgadas nos produtos da central, que estão mais relacionados a informações de cunho técnico, voltado para o aumento da eficiência e competitividade das propriedades rurais. Conteúdos de educação cooperativista aparecem com pouca frequência nas comunicações da cooperativa central com os produtores rurais. As principais informações que circulam da central para a cooperativa singular conforme relatos dos entrevistados são: tendências do mercado de leite; informações a respeito de mercado, tanto o preço pago ao produtor quanto a comercialização da Central.

Portanto, a capilaridade da central é proveniente das singulares que realizam mais atividades voltadas à gestão social cooperativa. Observou-se também que a central participa muito pouco das ações dos núcleos e dos comitês educativos das singulares, embora sejam âmbitos de comunicação potencialmente importantes, já que a maioria dos produtores que participam destas instâncias entrega o leite para a central. Se fosse bem implementada, a participação da central poderia ser um espaço de comunicação mais eficiente, visto que, além de poder informar melhor os produtores (face a face e não tanto por meios massivos de comunicação) sobre as tendências do mercado, notícias da própria central, capacitar sobre como produzir a qualidade do leite necessária, entre outros temas de interesse, poderia ter a retroalimentação de informações dos produtores sobre suas condições e dificuldades, a fim de ajustar a produção industrial e/ou poder estabelecer melhor as políticas e estratégias necessárias para solucionar os gargalos detectados. Dessa forma, com a informação chegando de forma mais rápida e em tempo real, os cooperados teriam mais condições de planejar da melhor forma possível a produção de leite e, a central, de ajustar suas estratégias produtivas de industrialização.

\section{Considerações finais}

No que se refere à política de comunicação com o produtor, os esforços da central são ainda recentes. Com a criação da assessoria de relacionamento com o produtor, há perspectivas de crescimento e importantes desafios pela frente, já que foca seus trabalhos em canais de baixo nível de riqueza, como os boletins e revistas, sem nenhuma circularidade da informação, contradizendo a natureza cooperativa que habilita em sua estrutura uma relação mais participativa e dialógica entre os partícipes do processo. Estes meios seriam complementares para fazer chegar as informações ao produtor, ainda mais se considerar o esforço desta assessoria em elaborar materiais informativos com conteúdos coerentes na linguagem do produtor rural, mas, por outro lado, ressalta-se a unilateralidade do fluxo de comunicação.

A proposta é que se aproveitem as instâncias participativas das singulares para realizar contatos face a face, por meio dos encarregados da assistência técnica. Essa seria uma alternativa de comunicação que melhor possibilitaria a troca de informações e que precisaria ser mais bem aproveitada pela central, uma vez que a comunicação face a face é o canal considerado mais rico e eficaz para se transmitir informações de diferentes naturezas. Os informantes das cooperativas entendem que seria preciso estabelecer uma política mais clara para potencializar o papel destes potenciais comunicadores, que estão mais em contato com a propriedade rural do produtor e podem apresentar maior interação e uma comunicação mais simétrica que qualquer um dos outros meios de comunicação baseados em tecnologias de massa. Numa avaliação sobre a comunicação da central, embora se reconheça o potencial das ações desenvolvidas, os informantes enfatizam que as cooperativas singulares têm mais possibilidades de se comunicar com os cooperados e lhes informar sobre questões do seu interesse devido à maior proximidade, sem que essa potencialidade seja devidamente explorada. 
Também foi observado que a cooperativa central participa muito pouco das ações dos comitês educativos das singulares, embora a maioria dos que participam destas instâncias entregue o seu leite para a central. Considera-se que este espaço poderia ser mais bem utilizado, possibilitando maior informação sobre as tendências do mercado, sobre as atividades da central, capacitando os produtores sobre produção de leite (qualidade/volume) que lhes permita ganhar mais mercados. Desse modo, a vantagem da Organização do Quadro Social é que as mensagens podem ser mais bem estruturadas, permitindo um processo que flexibilize simultaneamente os fluxos nos sentidos ascendentes e descendentes, permitindo-lhes mais eficiente e eficaz estruturação da cadeia láctea.

Uma das possíveis justificativas seria a insuficiente prática da educação cooperativista pelas cooperativas agrárias, em que se visualizam lacunas e dificuldades no direcionamento das atividades, além da falta de planejamento. A educação cooperativista é uma ferramenta essencial para promover a fidelização dos cooperados e o seu interesse em manter uma organização cada dia mais coesa e fiel às suas necessidades, sendo também uma ferramenta para aproximar interesses e necessidades dos cooperados e sua cooperativa. No entanto, trata-se de um trabalho exigente e, portanto, requer adequada gestão e recursos por parte da cooperativa singular, da central e dos próprios associados para poder manifestar toda sua potencialidade. A comunicação pode ser vista como uma ferramenta de auxílio para a gestão cooperativa, em especial, no processo de educação cooperativista, para atingir seus objetivos com base em seus princípios. Assim, esta pesquisa postula que a educação cooperativista e a comunicação devam andar juntas, como práticas indissociáveis do processo da gestão cooperativa, visando maior competitividade destas organizações.

Por fim, chega-se à conclusão de que o modelo de comunicação que mais se aproxima da realidade nas cooperativas singulares e da cooperativa central pesquisadas é o modelo como ação, que opera numa perspectiva unilateral. Foram constatados avanços na comunicação da central, sobretudo considerando que três anos antes não existia nenhuma política comunicacional. Apesar disso, é preciso reavaliar os atuais canais utilizados de nível mais pobre, comparando os dados da pesquisa encomendada pela central acerca do perfil dos produtores com os canais que têm mais condições de proporcionar uma retroalimentação de informações. Ainda é importante destacar o papel da Organização do Quadro Social nas cooperativas singulares como ferramenta para melhorar a comunicação e maximizar os fluxos de informações entre produtores-cooperativa singular-central. Assim, o modelo que mais se adequaria à estrutura específica das cooperativas, e também desta integração vertical, possibilitando desenvolver relações cooperado-cooperativa mais participativas e dialógicas, é o da comunicação como interação, que se propõe percorrer um caminho circular entre emissor e receptor. A sobrevivência deste modelo (Central - Singular) dependerá de como incorporar a comunicação voltada tanto para gestão empresarial quanto para a social seguindo a demanda do sistema agroindustrial, a fim de interligar e complementar a articulação dos interesses das três instâncias encontradas no modelo federado de cooperativas.

\section{Referências bibliográficas}

AMODEO, N. B. P. Contribuição da educação cooperativa nos processos de desenvolvimento rural. In: AMODEO, N. B. P. e ALIMONDA, H. (Orgs.). Ruralidades: capacitação e desenvolvimento. Viçosa: Ed. UFV, p. 151-176, 2006.

BABBIE, E. Métodos de pesquisa de survey. Belo Horizontes: UFMG, 1999.

BENECKE, D, W. Cooperação e desenvolvimento: o papel das cooperativas no processo de desenvolvimento econômico dos países do terceiro mundo. Porto Alegre: Coojornal, 1990.

BIALOSKORSKI NETO, S. Incentivos contratuais e eficiência: o caso da nova geração. Revista de Economia e Sociologia Rural, Brasília, v. 48, n. 4, p. 109-127, out/dez. 2000.

Aspectos econômicos das cooperativas. Belo Horizonte: Mandamentos, 2006. 
BYERS, P. Y. The process and perspectives of organizational communication. In: BYERS, P. Y. (Org.). Organizational communication: theory and behavior. Boston: Allynand Bacon, p.3-38, 1997.

CHADDAD, F. R. Cooperativas no Agronegócio do Leite: mudanças organizacionais e estratégias em resposta à globalização. Revista Organizações Rurais $e$ Agroindustriais, Lavras, v. 9, n. 1, p. 69-78, 2007.

COSTA, D.R. M., CHADDAD, R. R. e AZEVEDO, P. F. Separação entre Propriedade e Decisão de Gestão nas Cooperativas Agropecuárias Brasileiras. Revista de Economia e Sociologia Rural, Piracicaba, SP, v. 50, n. 2, p. 285-300, abr.jun. 2012.

CRÚZIO, H. O. Cooperativas em rede e autogestão do conhecimento. Rio de Janeiro: Editora FGV, 2006.

FERREIRA, P. R., AMODEO, N. B. P. e SOUSA, D. N. Os públicos atendidos e os conteúdos da educação cooperativista nas cooperativas agrárias. Revista Brasileira de Gestão e Desenvolvimento Regional, v. 9, p. 67-90, 2013.

FRANTZ, W. Comunicação e educação em cooperativas: retrospectiva histórica e importância atual. Perspectiva Econômica, São Leopoldo, ano XVII, v. 13, n. 39, 1983.

FREIRE, P. Extensão ou comunicação? Rio de Janeiro: Paz e Terra, 1983.

GIMENES, R. M. T. Agribusiness cooperativo: viabilidade econômica da abertura direta do capital pela emissão de debêntures. 2004. 207 f. Tese (Doutorado em Engenharia de Produção) - Universidade Federal de Santa Catarina, Florianópolis, 2004.

KUNSCH, M. M. K. Planejamento estratégico da comunicação. In: KUNSH, M. M. K. (Org.). Gestão estratégica em comunicação organizacional e relações públicas. São Caetano do Sul, SP: Difusão Editora, 2008, p. 107-124.

LITTLEJOHN, S. W. Fundamentos teóricos da comunicação humana. Rio de Janeiro: Guanabara, 1998.

MACEDO, A., AMODEO, N. B. P. e SOUSA, D. N. Gestão Social em Cooperativas Agropecuárias: análise do trabalho de Organização do Quadro Social (OQS). In: V Encontro Nacional de Pesquisa Social-ENAPEGs, 2011, Florianópolis - SC. Anais... Florianópolis: UFSC, 2011.

MACEDO, A. S., SOUSA, D. N. e AMODEO, N. B. P. O papel da comunicação na articulação dos diferentes níveis de organização no modelo central-singular de cooperativas. Bahia Analise \& Dados, v. 23, p. 89-105, 2013.
MATOS, H. Capital social e comunicação: interfaces e articulações. São Paulo: Summus, 2009.

NEHER, W. W. Organizational communication: challenges of change, diverstity and continuity. Boston: Allyn and Bacon, 1997.

OLIVEIRA, D. P. R. Manual de gestão das cooperativas: uma abordagem prática. 3.ed. São Paulo: Atlas, 2006.

PASQUALI, A. Sociologia e comunicação. Petrópolis: Vozes, 1973.

PINHO, J. B. Comunicação organizacional. Viçosa: UFV, 2006.

PUTNAM, L.L., PHILLIPS, N. e CHAPMAN. P. Metáforas da comunicação e da organização. In: CLEGG, S. R., HARDY, C. e NORD, W. R. (Orgs.). Handbook de estudos organizacionais: ação e análise organizacionais. São Paulo: Atlas, 2004.

REGO, F. G. T. Comunicação empresarial, comunicação institucional: conceitos, estratégias, sistemas, estrutura, planejamento e técnicas. 5. ed. São Paulo: Summus, 2000.

RICCIARDI, L. e LEMOS, R. J. Cooperativa, a empresa do século XXI: como os países em desenvolvimento podem chegar a desenvolvidos. São Paulo: LTr, 2000.

ROBBINS, S. P. Fundamentos do comportamento organizacional. 7. ed. São Paulo: Prentice Hall, 2004.

SCHMITZ, V. R. Comunicação nas cooperativas: seus diferentes públicos e instrumentos. In: SCHNEIDER, J. O. (Org.). Educação cooperativa e suas práticas. Brasília: Unisinos, p. 195-205, 2003.

SCHNEIDER, J. O. Principais problemas na comunicação cooperativa. In: PINHO, D. (Org.). Administração de cooperativas. São Paulo: CNPq, p. 141145, 1982.

. Pressupostos da educação cooperativista: a visão de sistematizadores da doutrina do cooperativismo. In: SCHNEIDER, J. O. (Org.). Educação cooperativista e suas práticas. Brasília: Unisinos, p. 13-58, 2003.

. e HENDGES, M. Educação e Capacitação Cooperativa: sua importância e aplicação. Economia Solidária e Ação Cooperativa, v. 1, n. 1, p. 33-48, 2006.

SOUSA, D. N., AMODEO, N. B. P. e MACEDO, A. S. "O atual modelo de captação de leite é adequado ?": Compreendendo a articulação agroindustrial no modelo federado de cooperativas. In: MILAGRES, C. S. F. e SOUSA, D. N. S. (Orgs.). Cooperativismo, Extensão Rural e processos Participativos. Palmas: Ed. UFT, 2014, p. 7-19 
514 - A Comunicação na Articulação Agroindustrial entre Uma Cooperativa Central, suas Cooperativas Singulares e Cooperados

VALADARES, J. H. Cooperativismo: lições para nossa prática. Brasília: OCB, 2003.

Estratégias de educação para a cooperação. Rio de Janeiro: FGV - MBA em Gestão empresarial de Cooperativas, 2009.
VALENTINOV, V. Toward a social capital theory of cooperative organization. Journal of Cooperative Studies, v. 37, n. 3, p. 5-20, 2004.

ZYLBERSTAJN, D. Quatro estratégias fundamentais para cooperativas agrícolas. São Paulo: USP, 2002. 